\title{
Unusual Behavior during Cannibalism of Cuban Treefrogs (Osteopilus septentrionalis) in a Commensal Habitat in Cuba
}

\author{
Rafael Borroto-Páez ${ }^{1}$ and Denise Reyes Pérez ${ }^{2}$
}

1Sociedad Cubana de Zoología, AP 11900, La Habana, Cuba (borroto@yahoo.com)

${ }^{2}$ Instituto de Geografía Tropical, Calle F entre 13 y 15, Vedado, La Habana, Cuba

The Cuban Treefrog (Osteopilus septentrionalis, Hylidae)

1 is native in Cuba, the Cayman Islands, and at least eight Bahamian islands (Henderson and Powell 2009). It also has been introduced widely to many Caribbean Islands, Costa Rica, and the US states of Florida, Georgia, and Hawaii (Owen et al. 2005; Henderson and Powell 2009; Powell et al. 2011, 2013).

In the Cuban Archipelago, the Cuban Treefrog is widely distributed on the main island and on at least 15 offshore islands, where it is relatively abundant (Estrada 2012; Rivalta González et al. 2014). It occupies both natural and anthropogenic habitats. In Cuban villages and rural areas, the Cuban Treefrog often functions as a human commensal. However, studies of this species focus largely on introduced populations (e.g., Meshaka 1996, 2001; Owen 2005; Smith 2005; Vargas Salinas 2006).

Cannibalism in frogs has been documented in many anurans (e.g., Crump 1992; Toledo et al. 2007; Measey et al.
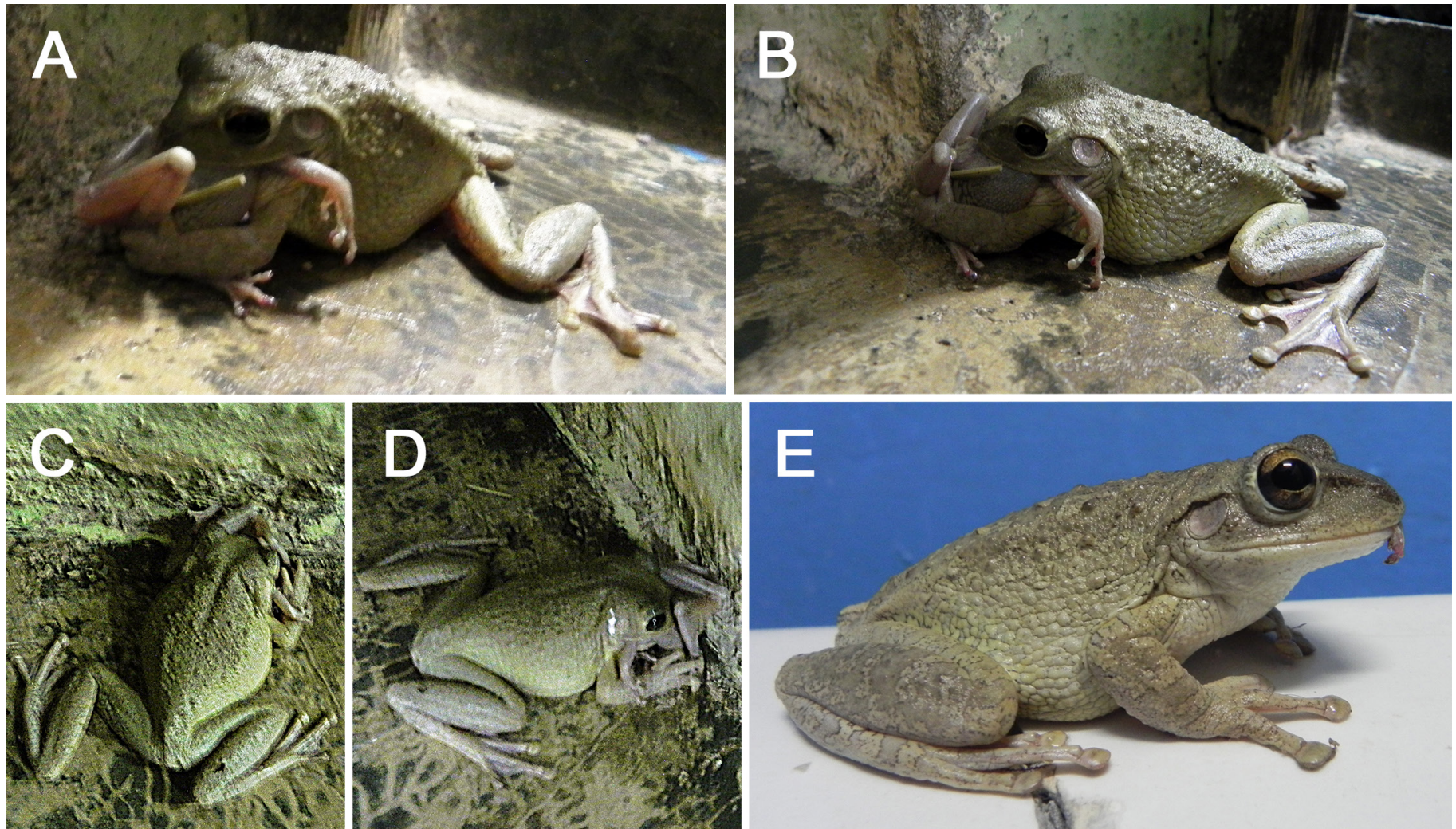

Fig. 1. Cannibalism in Cuban Treefrogs (Osteopilus septentrionalis) in a commensal habitat in the village of Ategorrieta, Matanzas Province. A large female partially ingesting a smaller conspecific (A), the female repeatedly pushing against a wall to facilitate ingestion of the prey (B-D), and the female 45 min later with a small portion of the prey's toe emerging from its mouth (E). Photographs by the senior author. 
2015). Several instances of cannibalism by dietary opportunistic Cuban Treefrogs have been reported in introduced populations (e.g., Peters 1974; Meshaka 1996, 2001; Glorioso et al. 2012; Johnson 2013; Herman et al. 2015) but only recently in the species' native habitat in Cuba (Kaiser et al. 2016).

Herein we report a second instance of cannibalism in Osteopilus septentrionalis in Cuba and the first in a commensal habitat. At $2230 \mathrm{~h}$ on 31 December 2018, in the village of Ategorrieta village $\left(22^{\circ} 56^{\prime} 28^{\prime \prime} \mathrm{N}, 80^{\circ} 57^{\prime} 03^{\prime \prime} \mathrm{W}\right.$; elev. $37 \mathrm{~m}$ asl), $2 \mathrm{~km}$ west of Marti, Matanzas Province, we observed an adult female (75 mm SVL) trying to ingest a conspecific (Fig. $1 \mathrm{~A})$, presumably a male based on body size. When we initially encountered the frogs, the female had ingested almost half of the body of the smaller frog (Fig. 1A-B) and was pushing it against a wall in an apparent attempt to force the prey into its mouth (Fig. 1B). Pushing against a wall was repeated three or four times (Fig. 1C-D) and was accompanied by efforts to ingest its prey using its forelimbs. After $45 \mathrm{~min}$, the female entered a bathroom and climbed on to a sink and later a toilet tank with only a tip of the prey's toe emerging from her mouth (Fig. 1E). Two other frogs, both males, were on the walls of the bathroom during this encounter.

We found no other references to feeding behavior involving the use of a wall or other object to facilitate ingestion of prey by a Cuban Treefrog. A high density of conspecifics in such a commensal environment might increase the incidence of cannibalism, which provides food while simultaneously reducing competition (e.g., Kaiser et al. 2016).

\section{Acknowledgements}

We thank Boris A. Fabres, Environmental Protection in the Caribbean (EPIC), for reviewing an early version of this manuscript and providing useful suggestions that improved it.

\section{Literature Cited}

Crump, M.L. 1992. Cannibalism in amphibians, pp. 256-276. In: M.A. Elgar and B.J. Crespi (eds.), Cannibalism: Ecology and Evolution among Diverse Taxa. Oxford University Press, Oxford, United Kingdom.

Estrada, A.R. 2012. The Cuban Archipelago, pp. 113-125. In: R. Powell and R.W. Henderson (eds.), Island lists of West Indian amphibians and reptiles. Bulletin of the Florida Museum of Natural History 51: 85-166.

Glorioso, B.M., J.H. Waddle, M.W. Crockett, K.G. Rice, and H.F. Percival. 2012. Diet of the invasive Cuban Treefrog (Osteopilus septentrionalis) in pine rockland and mangrove habitats in South Florida. Caribbean Journal of Science 46: 346-355.

Henderson, R.W. and R. Powell. 2009. Natural History of West Indian Reptiles and Amphibians. University Press of Florida, Gainesville, Florida.

Herman, J.E., A. Benton, and I.N. Irizarry. 2015. Osteopilus septentrionalis (Cuban Treefrog). Cannibalism. Herpetological Review 46: 75-76.

Johnson, S.A. 2013. The Cuban Treefrog (Osteopilus septentrionalis) in Florida. WEC218, Second Revision. Department of Wildlife Ecology and Conservation, University of Florida/Institute of Food and Agricultural Sciences Extension, Gainesville, Florida.

Kaiser, H., M.C. Chamberlain, T. Edwards, J.R. Nuñez, T.M. Rodríguez-Cabrera, and J. Torres. 2016. Cannibalism in Cuba: First direct observations of Cuban Treefrogs (Osteopilus septentrionalis, Hylidae) feeding on conspecifics in their native habitat, with a brief review of anurophagy and cannibalism in treefrogs. Reptiles \& Amphibians 23: 21-27.

Measey, G.J., G. Vimercati, F.A. de Villiers, M.M. Mokhatla, S.J. Davies, S. Edwards, and R. Altwegg. 2015. Frog eat frog: Exploring variables influencing anurophagy. PeerJ 3: e1204.

Meshaka, W.E., Jr. 1996. Diet and colonization of buildings by the Cuban Treefrog, Osteopilus septentrionalis (Anura: Hylidae). Caribbean Journal of Science 32: 59-63.

Meshaka, W.E., Jr. 2001. The Cuban Treefrog in Florida: Life History of a Successful Colonizing Species. University of Florida Press, Gainesville, Florida.

Owen, J.L. 2005, The Cuban Tree Frog (Osteopilus septentrionalis): Distribution, diet, and reproduction of an invasive species in the British Virgin Islands. Unpublished M.S. Thesis, Texas Tech University, Lubbock, Texas.

Owen J., G. Perry, J. Lazell, C. Petrovic, and J. Egelhoff. 2005. Osteopilus septentrionalis. Geographic distribution, British Virgin Islands. Herpetological Review 36: 76.

Peters, G. 1974. Notizen über die Batrachofauna der Insel Kuba. Mitteilungen aus dem Zoologischen Museum in Berlin 50: 299-322.

Powell, R., R.W. Henderson, M.C. Farmer, M. Breuil, A.C. Echternacht, G. van Buurt, C.M. Romagosa, and G. Perry. 2011. Introduced amphibians and reptiles in the Greater Caribbean: Patterns and conservation implications, pp. 63-143. In: A. Hailey, B.S. Wilson, and J.A. Horrocks (eds.), Conservation of Caribbean Island Herpetofaunas. Volume 1: Conservation Biology and the Wider Caribbean. Brill, Leiden, The Netherlands.

Powell, R., R.W. Henderson, G. Perry, M. Breuil, and C.M. Romagosa. 2013. Introduced amphibians and reptiles in the Lesser Antilles, pp. 74-107. In: J.-L. Vernier and M. Burac (eds.), Biodiversité Insulaire: la Flore, la Faune et l'Homme dans les Petites Antilles. Actes du Colloque international, Schoelcher, 8-10 Novembre 2010. Direction de l'Environment, de l'Aménagement et du Logement de Martinique and Université de Antilles et de la Guyana, Schoelcher, Martinique.

Rivalta González, V., L. Rodríguez Schettino, C.A. Mancina, and M. Iturriaga. 2014. Amphibians of Cuba: Checklist and geographic distribution. Smithsonian Herpetological Information Service 145: 1-48.

Smith, K.G. 2005. Nonindigenous Herpetofauna of Florida: Patterns of Richness and Case Studies of the Impacts of the Tadpoles of Two Invasive Amphibians, Osteopilus septentrionalis and Bufo marinus. Unpublished Ph.D. Dissertation, University of Tennessee, Knoxville, Tennessee.

Toledo, L.F., R.S. Ribeiro, and C.F.B. Haddad. 2007. Anurans as prey: An exploratory analysis and size relationships between predators and their prey. Journal of Zoology 271: 170-177.

Vargas Salinas, F. 2006. Breeding behavior and colonization success of the Cuban Treefrog Osteopilus septentrionalis. Herpetologica 62: 398-408. 